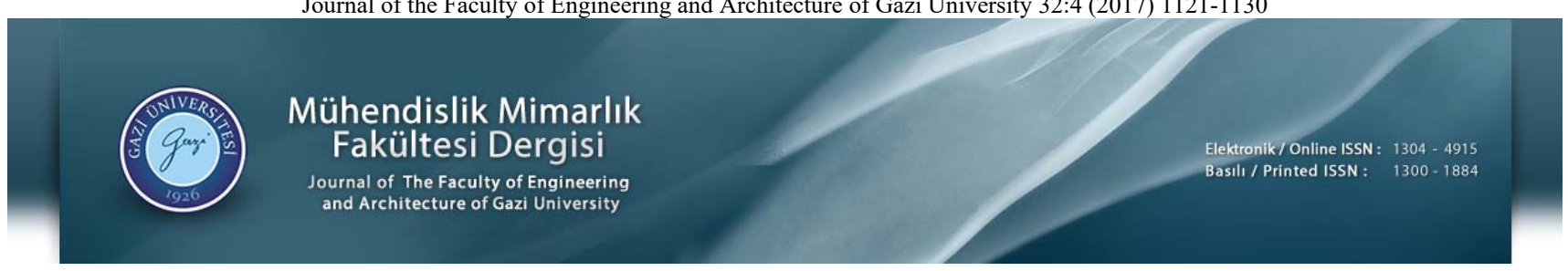

\title{
MSMPR tipi kristalizörde kalsiyum sülfat dihidrat kristalizasyonunun glutamik asit varlığında incelenmesi
}

Sevgi Polat (iD), Perviz Sayan (D)*, Sibel Titiz Sargut (D)

Marmara Üniversitesi, Mühendislik Fakültesi, Kimya Mühendisliği Bölümü, 34722, İstanbul, Türkiye

Ö N E Ç I K A N L A R

- Kalsiyum sülfat dihidrat kristalizasyon kinetiği

- Kristal ürünün karakterizasyonu

- $\quad$ ASL, C-R, MJ2 ve MJ3 kinetik modeller

Makale Bilgileri

Geliş: 01.07.2016

Kabul: 10.08.2017

DOI:

10.17341/gazimmfd.369501

Anahtar Kelimeler:

Kalsiyum sülfat dihidrat, glutamik asit,

kristalizasyon kinetik

modelleri,

karakterizasyon

\section{ÖZET}

$\mathrm{Bu}$ çalışmada, kalsiyum sülfat dihidrat kristalizasyonu, $65^{\circ} \mathrm{C}$ sıcaklıkta, $\mathrm{pH} 2,5^{\text {' }}$ da ve 0,5 saat bekleme süresinde MSMPR tipi bir kristalizörde saf ve glutamik asit varlığında incelenmiştir. Bu amaçla \%20'lik $\mathrm{CaCO}_{3}$ ve $\mathrm{H}_{2} \mathrm{SO}_{4}$ çözeltisi kullanılarak saf ortamda ve 250 ppm, 1000 ppm ve 2500 ppm glutamik asit varlığında kristalizasyon deneyleri yürütülmüsştür. Elde edilen kristal ürünün tane boyutu, filtrasyon hızı ve zeta potansiyel değişimi ölçülmüş, XRD, TG-FTIR-MS, SEM analizleri yapılmıştır. Glutamik asidin kristalizasyon ortamında bulunması durumunda üretilen kalsiyum sülfat dihidrat kristallerinin en/boy oranlarının değiştiği, filtrasyon hızının azaldığı ve ortalama tane boyutunun glutamik asit konsantrasyonunun artışına bağlı olarak $73 \mu \mathrm{m}$ 'den $54 \mu \mathrm{m}$ 'ye düştüğü belirlenmiştir. İncelenen koşullarda kalsiyum sülfat dihidratın kristalizasyon kinetiği McCabe'in $\Delta \mathrm{L}$ teorisine göre belirlenmiş ve kristal büyüme hızının tane boyutuna bağlı olduğu gösterilmiştir. Ayrıca ASL, C-R, MJ2 ve MJ3 büyüme modelleri kullanılarak kristal büyüme hızı belirlenmiştir. Yapılan hata analizleri sonucunda MJ3 modelinin sistemi en iyi karakterize eden model olduğu bulunmuştur. Sem analizleri ile de glutamik asidin kristal habiti üzerine olan etkisi gösterilmiştir.

\section{Investigation of calcium sulfate dihydrate crystallization in the presence of glutamic acid in MSMPR crystallizer}

\section{H I G H L I G H T S}

- The crystallization kinetics of calcium sulfate dihydrate

- The characterization of the crystal products

- $\quad$ ASL, C-R, MJ2 and MJ3 kinetic models

Article Info

Received: 01.07.2016

Accepted: 10.08 .2017

DOI:

10.17341/gazimmfd.369501

Keywords:

Calcium sulfate dihydrate, glutamic acid, crystallization kinetic models,

characterization

\section{ABSTRACT}

In this study, calcium sulfate dihydrate crystallization was performed in a laboratory scale mixed-suspension mixed-product removal (MSMPR) crystallizer at $2.5 \mathrm{pH}, 65^{\circ} \mathrm{C}$ and $\tau=0.5$ hour in the absence and the presence of glutamic acid. The experiments were carried out at different glutamic acid concentrations as 250 $\mathrm{ppm}, 1000 \mathrm{ppm}$ and $2500 \mathrm{ppm}$ by the reaction of calcium carbonate solution $(20 \% \mathrm{w} / \mathrm{w})$ with sulfuric acid $(20 \% \mathrm{w} / \mathrm{w})$ solution. The crystal size distributions, filtration rates and zeta potentials of the crystals obtained were measured and the crystals were analyzed by XRD, TGA-FTIR-MS and SEM. It was determined that the width/length ratio of the calcium sulfate dihydrate crystals changed, the filtration rate decreased and the average particle size decreased from $73 \mu \mathrm{m}$ to $54 \mu \mathrm{m}$ depending on increasing glutamic acid concentration. The calcium sulfate dihydrate crystallization kinetic was examined on the basis of McCabe's $\Delta \mathrm{L}$ law and the crystal growth was found to be dependent on crystal size. Furthermore, the growth rate of crystals was determined using ASL, C-R, MJ2, and MJ3 model. By comparison of the results of mean square error analysis, it was found that the MJ3 model was the best model to characterize the system. The effect of glutamic acid on the crystal habit was also shown by SEM analysis. 


\section{GİRIŞ (INTRODUCTION)}

Kalsiyum sülfat dihidrat $\left(\mathrm{CaSO}_{4} \cdot 2 \mathrm{H}_{2} \mathrm{O}\right.$, Jips $)$ kolemanitten borik asit ve kalsiyum fosfattan fosforik asit üretiminde yan ürün olarak ortaya çıkan ve filtrasyonundaki problemler nedeni ile proses verimini etkileyen önemli bir maddedir. Kalsiyum sülfat dihidratın sudaki çözünürlüğünün sıcaklıkla azalması her iki proseste de prosesin yavaşlamasına ve hatta durmasına sebep olmaktadır. Bu durum ayrıca proses veriminin azalmasına neden olarak nihai ürün içinde yüksek oranda safsızlık problemlerinin ortaya çıkmasına neden olmaktadır [1]. Bu nedenle, kolay filtrelenebilir kalsiyum sülfat dihidrat üretimi her iki proseste de ürünlerin daha saf ve yüksek kalitede elde edilmesi açısından büyük önem taşımaktadır. Filtrasyon hızı, kristal ürün tane dağılımına, kristalin morfolojisine ve kristal boyutuna bağlı olarak proseste de değişebilmektedir. Öte yandan kalsiyum sülfatın sudaki çözünürlüğünün sicaklıkla ters orantılı olarak değişimi, borularda, tanklarda ve isı değiştiricilerde kabuk oluşumu sorununu ortaya çıkarmaktadır. $\mathrm{Bu}$ kabukların temizlenmesi hem maliyeti hem de proses verimini etkilemesi nedeniyle istenmeyen bir durumdur [2]. Bu nedenle kalsiyum sülfatın kabuk oluşumunun önlemesi, geciktirilmesi veya kalsiyum sülfatın yan ürün olarak elde edildiği proseslerde kolay filtrelenebilir olması oldukça önemlidir [3]. Kalsiyum sülfat dihidratın proses ekipmanlarında oluşturduğu sorunlar; kabuk oluşumunun gerçekleşmediği proses şartlarının tespiti, iyon değiştirici kullanımı ile kabuk oluşumuna sebep olan katyonların uzaklaştırılması veya prosese modifiye edici katkıların ilavesi ile giderilebilmektedir. Ancak, uygulanabilirlik açısından kolay olması ve ekonomik açıdan daha ucuz olması nedeniyle katkı maddesi kullanımı tercih edilmektedir [4]. Bu nedenle, kalsiyum sülfat dihidrat kristalizasyonu üzerine modifiye edici farklı inorganik ve organik yapıdaki maddeler literatürde incelenmiştir.
Feldmann vd. [5] $\mathrm{K}^{+}, \mathrm{Mg}^{+2}, \mathrm{Sr}^{+2}, \mathrm{Ba}^{+2}, \mathrm{Al}^{+3}, \mathrm{Fe}^{+2}, \mathrm{Fe}^{+3}$ metallerinin kalsiyum sülfat dihidrat kristalizasyonuna etkisini incelemiş ve kristal morfolojisini etkilediğini ortaya koymuşlardır. Ben Ahmed vd. [6] akrilik asidin farklı çalışma koşullarında kalsiyum sülfat dihidrat kristal büyüme hızına etkisini incelemiş; akrilik asit konsantrasyonunun artmasıyla nükleasyon hızının azaldığını belirlemişlerdir. Titiz-Sargut vd. [1] sitrik asidin kalsiyum sülfat dihidrat kristallerinin ortalama tane boyutuna ve filtrasyon karakteristiğine olan etkisini incelemiş, sitrik asidin elde edilen kristallerinin ortalama tane boyutu ve şeklini değiştirdiğini ortaya koymuşlardır. Literatürde verilen katkı maddelerinin kalsiyum sülfatın morfolojik yapısı üzerindeki değişimi gösterilmiş olmasına rağmen büyüme kinetiği ile ilgili önemli eksikler bulunmaktadır. Bu çalışmada hem bu eksiklikleri gidermek hem de daha önce etkisi incelenmeyen ekonomik, kolay erişilebilir, zehirli olmayan ve biyolojik olarak bozunabilen glutamik asit katk1 maddesi olarak seçilmiştir. Saf ortamda ve seçilen katkı varlığında üretilen kalsiyum sülfat dihidratın ortalama tane boyutunda, morfolojisinde ve filtrasyon karakteristiğinde meydana gelen değişimler incelenmiştir. Ayrıca farklı kinetik modelleri kullanılarak büyüme hızı değişimi saptanmıştır.

\section{DENEYSEL METOT (EXPERIMENTAL METHOD)}

$\mathrm{Bu}$ çalışmada kalsiyum sülfat dihidrat kristalizasyonu ağırlıkça \%20 kalsiyum karbonat $\left(\mathrm{CaCO}_{3}\right)$ çözeltisi ve \%20 sülfürik asit $\left(\mathrm{H}_{2} \mathrm{SO}_{4}\right)$ çözeltisi kullanılarak MSMPR tipi bir kristalizörde gerçekleştirilmiştir. Kristalizör 1L hacme sahip olup literatürde bu konuda yapılan çalışmalarda kullanılan kristalizörlerdeki standart özelliklere sahiptir [7]. Deney düzeneği Şekil 1'de verilmiştir.

Reaktanlar kristalizöre peristaltik pompalar aracılı̆̆ıla beslenmiştir. Kristalizör içinin sıcaklığı termostat yardımıyla

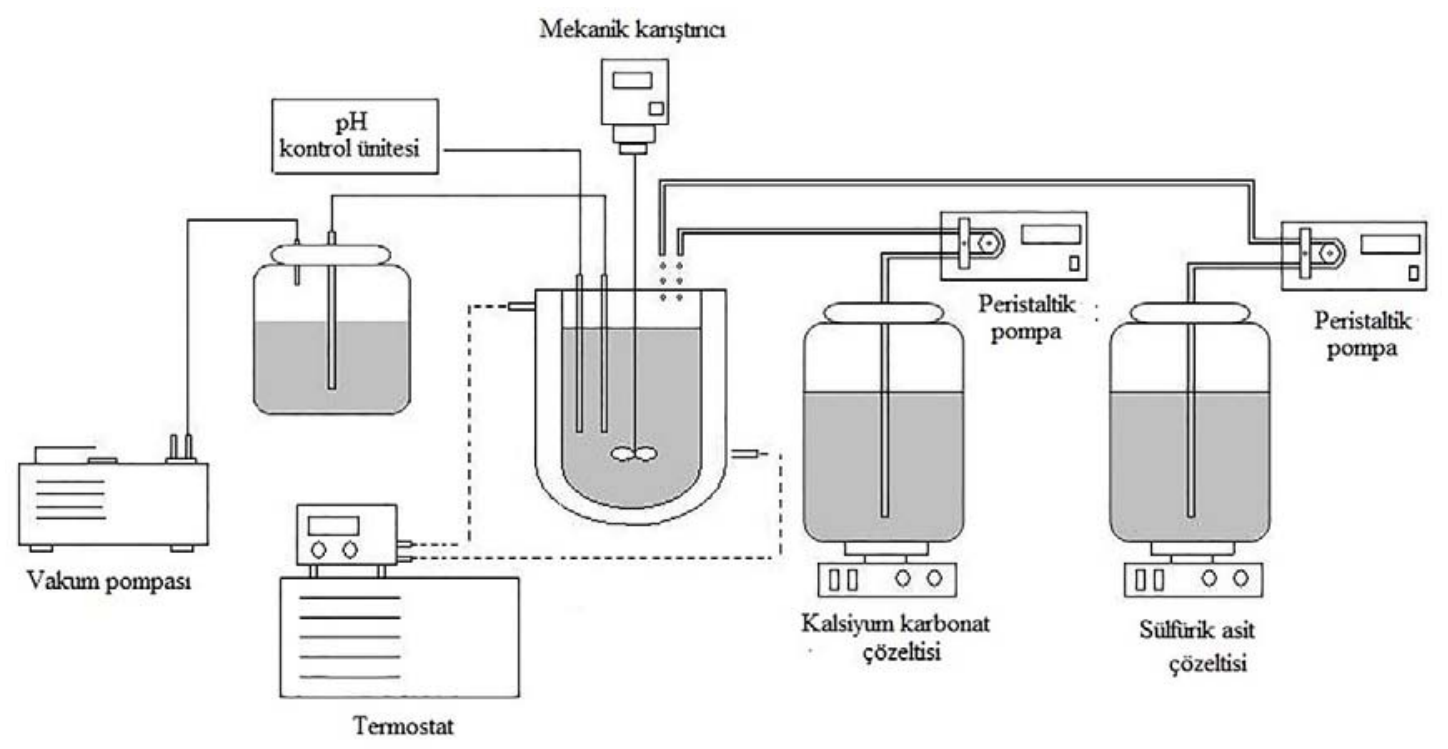

Şekil 1. Deney düzeneği (Experimental set-up) 
$65^{\circ} \mathrm{C}$ 'de sabit tutulmuştur. Kristalizör içinin $\mathrm{pH}$ '1 sürekli olarak ölçülmüş ve bir kontrol edici vasıtası ile 2,5 pH'da sabit tutulmuştur. Karıştırma işlemi üç kanatlı bir karıştırıcı eleman yardımı ile 650 rpm karıştırma hızında yapılmıştır. Deneylerde katkı malzemesi olarak kullanılan glutamik asit kristalizör içerisine \%20'lik $\mathrm{H}_{2} \mathrm{SO}_{4}$ çözeltisi ile birlikte beslenmiştir. Katkı malzemesi konsantrasyonu olarak 250 ppm, 1000 ppm ve 2500 ppm olmak üzere üç farklı glutamik asit konsantrasyonu seçilmiştir. Deney süresince kristalizörde kalma süresine bağlı olarak belirli zaman aralıklarında tane sınıflanmasına neden olmayacak şekilde vakum pompası yardımı ile ürün çekilmiştir. Kristal ürün çekim hızı, kristal tane boyutu dağılımlarındaki değişim göz önüne alınarak daha önceden yapılan ön deneyler ile belirlenmiş ve bu belirlenen izo kinetik hızda numune çekimleri gerçekleştirilmiştir. Literatürde MSMPR tipi bir kristalizörde kristal ürünün tane dağılımının değişmediği ve kararlı hale gelmesi için gerekli olan sürenin kalma süresinin 6-8 katı arasında olduğu gösterilmiştir [7]. Bu nedenle bu çalışmada da kristalizasyon süresi kalma süresinin 8 katı olarak seçilmiştir. Bu sürenin sonunda kristalizör içeriğini karakterize eden karakteristik numuneler alınmış, tane boyu analizleri ve filtrasyon karakteristikleri belirlenmiştir. Tane boyut analizi için lazer kırınımlı tane boyut analiz cihazı (Malvern 2000), filtrasyon hızı ölçümleri için ise standart vakum filtrasyon ünitesi kullanılmıştır. Ayrıca glutamik asit varlığında elde edilen kalsiyum sülfat dihidratın zeta potansiyel değişimi incelenmiş, XRD, TGA-FTIR-MS ve SEM analizleri yapılmıştır.

\section{SONUÇLAR VE TARTIŞMALAR (RESULTS AND DISCUSSIONS)}

Spesifik kek direncindeki değişim kristal tane boyutu ve kristal morfolojisinde meydana gelen değişimin bir göstergesidir. Tane boyutunun düşmesi spesifik kek direncinin artmasına, morfolojik yapı değişimleri ise değişimin cinsine bağlı olarak hesaplanan spesifik kek direncinin artmasına veya azalmasına neden olmaktadır. $\mathrm{Bu}$ nedenle, bu çalışmada her iki durumunda etkisini belirleyebilmek açısından saf ve farklı glutamik asit konsantrasyonlarında elde edilen kristal ürünün ortalama tane boyutu, spesifik kek direnci ve morfolojik değişimleri belirlenmiş ve sonuçlar Şekil 2 ve Şekil 3'de verilmiştir.

Şekil 2'den görüldüğü üzere, saf ortamda kalsiyum sülfat dihidrat kristallerinin ortalama tane boyutu $73 \mu \mathrm{m}$ olarak belirlenmiş, spesifik kek direnci $1,01 \times 10^{10} \mathrm{~m} / \mathrm{kg}$ olarak hesaplanmıştır. Glutamik asit konsantrasyonunun artmasıyla birlikte ortalama tane boyutu azalmış, spesifik kek direnci ise artmıştır Spesifik kek direncinde meydana gelen artış filtrasyon hızının düştüğünün bir göstergesidir. Ancak, bu çalışmada spesifik kek direncinde görülen artışın sadece tane boyutuna bağlı olarak gerçekleşmediği aynı zamanda kalsiyum sülfat dihidratın kristal habitinde meydana gelen değişimlere bağlı olarak ortaya çıktığı belirlenmiştir. Bu nedenle, kristal habitinde meydana gelen değişimi daha iyi ortaya koyabilmek açısından SEM fotoğrafları çekilmiştir.

Şekil 3'de saf ortamda ve 2500 ppm glutamik asit varlığında üretilen kalsiyum sülfat dihidrat kristallerinin SEM görüntüleri verilmiştir. Şekil 3'den görüleceği üzere, saf ortamda üretilen kalsiyum sülfat dihidrat kristalleri düzgün iğne yapılı bir forma sahiptir. Glutamik asit varlığında elde edilen kristallerin, iğne görünümlü yapısını korumakla birlikte en ve boy oranlarının değiştiği belirlenmiştir. Bu değișim saf ortama göre kristal boyunda kısalma eninde ise daralma şeklinde gerçekleşmiştir. En ve boy oranlarında meydana gelen değişimin sonucu olarak ortalama tane boyutu $73 \mu \mathrm{m}$ 'den $54 \mu \mathrm{m}$ 'ye düşmüş, spesifik kek direnci ise $1,01 \times 10^{10} \mathrm{~m} / \mathrm{kg}$ 'dan $3,59 \times 10^{10} \mathrm{~m} / \mathrm{kg}$ 'a artmıştır. Aynı zamanda, glutamik asit konsantrasyonunun artışına bağlı olarak ortaya çıkan yapısal bozukluklar aglomerasyon eğilimi artışına neden olmuştur.

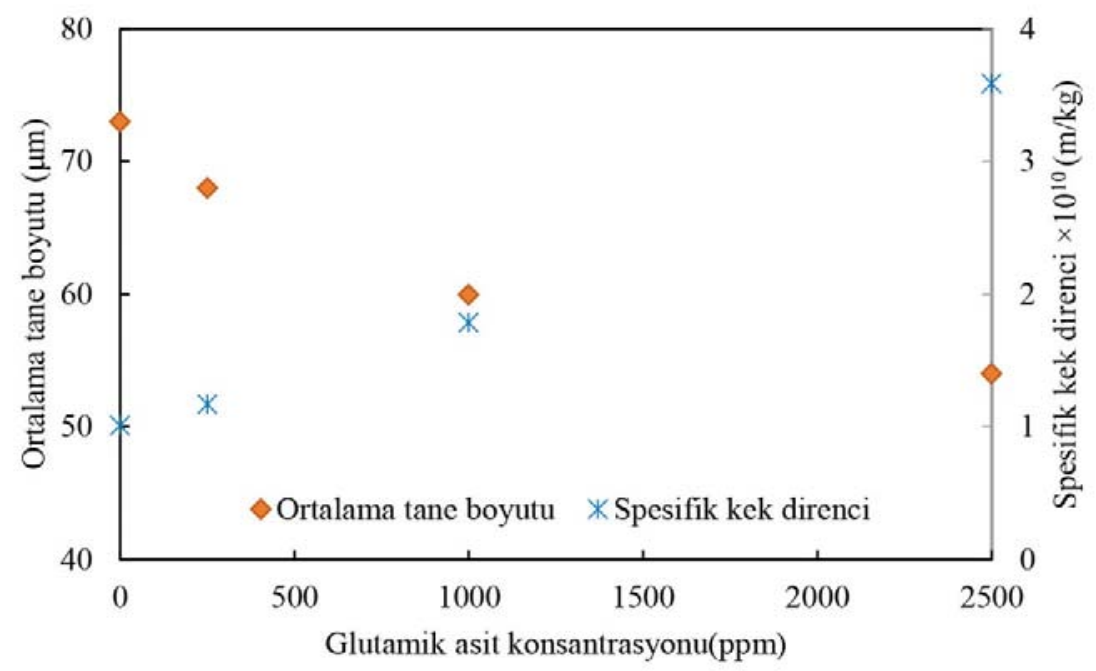

Şekil 2. Kalsiyum sülfat dihidrat kristallerinin glutamik asit konsantrasyonuna bağlı ortalama tane boyutu ve spesifik kek direnci değişimi (The changes of the average particle size and the specific cake resistance of the calcium sulfate dehydrate crystals according to glutamic acid concentration) 

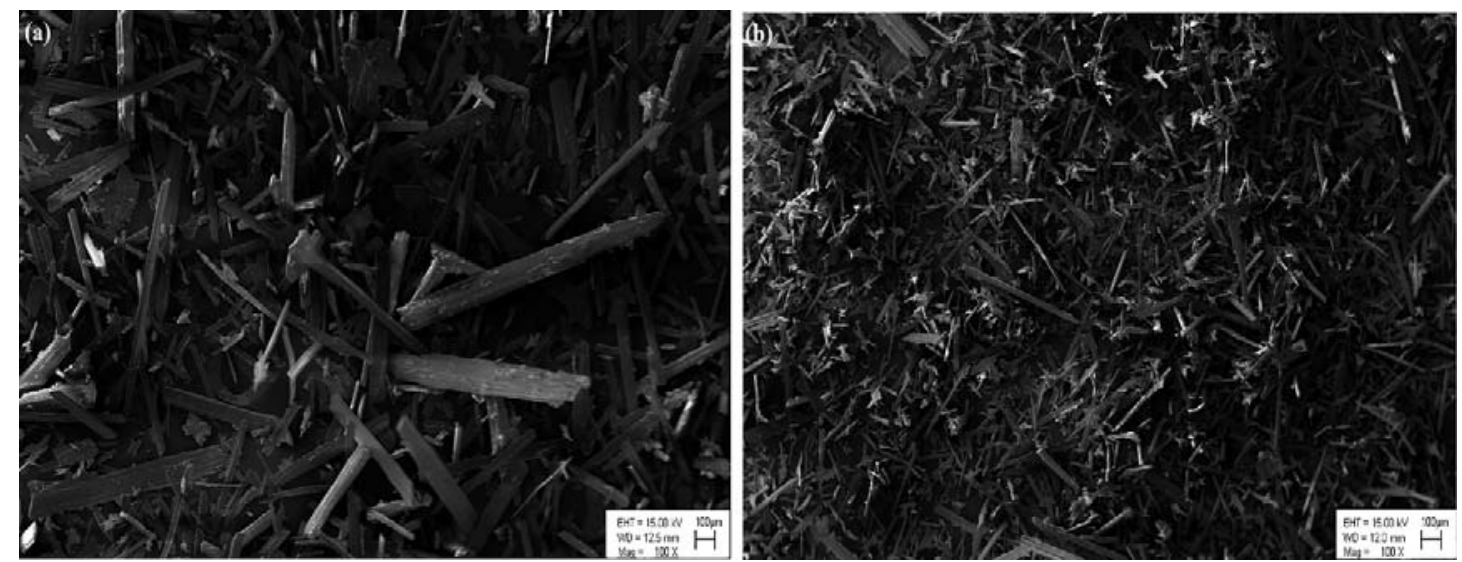

Şekil 3. Kalsiyum sülfat dihidrat kristallerinin SEM görüntüleri a) Saf ortam b) 2500 ppm glutamik asit (SEM images of the calcium sulfate dihydrate crystals (a) pure media (b) 2500 ppm glutamic acid)

Oluşan bu zayıf aglomereler ortamın hidrodinamik şartları tesiriyle kolaylıkla kırılarak hem ortalama tane boyutunun düşmesine hem de süspansiyon ortamının reolojik davranışını değiştirerek filtrasyon hızının azalmasına ve spesifik kek direncinin artmasına neden olmuştur. Kalsiyum sülfat dihidratın glutamik asit konsantrasyonuna bağlı zeta potansiyeli değişimi Şekil 4'de verilmiştir. Şekil 4'den görüldüğü üzere, saf ortamda kalsiyum sülfat dihidrat kristallerinin zeta potansiyeli $-13,3 \mathrm{mV}$ olarak ölçülmüştür. Kristalizasyon ortamında, pH'ın 6'dan düşük olduğu durumda glutamik asidin yapısında bulunan amin grubu protonlanmakta $\left(-\mathrm{NH}_{3}{ }^{+}\right)$ve negatif yüzey yüküne sahip kalsiyum sülfat dihidrat kristal yüzeyini kaplayarak yüzey potansiyelinin değişimine neden olmaktadır. Bu değişim glutamik asit konsantrasyonunun artışına bağlı olarak daha etkin hale gelmektedir.

$\mathrm{Bu}$ çalışmada, kalsiyum sülfat dihidratın glutamik asit varlığında ölçülen zeta potansiyel değerinin konsantrasyon artışıyla izoelektrik noktaya yaklaştığı görülmüştür. İzoelektrik noktada yük etkisinin ortadan kalktığı göz önüne alındığında, kristal aglomerasyonunun artması beklenen bir durum olacaktır. Nitekim SEM fotoğraflarında da görülen ve konsantrasyon artışına bağlı olarak ortaya çıkan zayıf aglomerelerin varlığı da ortaya konulan bu düşünceyi destekler niteliktedir. $\mathrm{Bu}$ çalışmada MSMPR tipi kristalizörde saf ve 2500 ppm glutamik asit varlığında üretilen kalsiyum sülfat dihidrat kristallerinin termogravimetrik analizi yapılmıştır. Termal analiz işlemi 10 mg numune kullanılarak $25-1000^{\circ} \mathrm{C}$ sicaklık aralığında, $10^{\circ} \mathrm{C} / \mathrm{min}$ 1sitma hizında ve azot atmosferinde gerçekleştirilmiştir. Şekil 5'de saf ve 2500 ppm glutamik asit varlığında elde edilen kalsiyum sülfat dihidratın termogramları ve DTG eğrileri verilmiştir. Şekil 5'de verilen termogramlar saf ve 2500 ppm glutamik asit varlığında üretilen kalsiyum sülfat dihidratın dehidrasyon reaksiyonu sonucunda meydana gelen kütle kaybının \%20 olduğunu ve termal bozunma açısından benzer davranış gösterdiğini ortaya koymuştur. DTG eğrilerinden de açıkça görüleceği üzere dehidrasyon süreci birbirini takip eden iki aşamada gerçekleşmektedir. Birinci aşamada kalsiyum sülfat dihidrat, hemihidrata ikinci aşamada ise susuz kalsiyum sülfata dönüşmektedir [8]. Saf kalsiyum sülfat dihidratın termogravimetrik analizi, \%11'lik ilk kütle kaybının 99$150^{\circ} \mathrm{C}$ sicaklık aralığında, ikinci kütle kaybının ise 150$175^{\circ} \mathrm{C}$ sıcaklık aralığında gerçekleştiğini ve \%9 olduğunu ortaya koymuştur. Glumatik asit varlığında üretilen kalsiyum sülfat dihidratın TGA ve DTG eğrileri aynı zamanda dehidrasyonun reaksiyonunun başlangıç ve bitiş noktalarının da ötelendiğini göstermiştir. Bu ötelenme başlangıç sıcaklığı için $100^{\circ} \mathrm{C}^{\prime}$ den $85^{\circ} \mathrm{C}$ 'ye; bitiş sıcaklığı ise $175^{\circ} \mathrm{C}$ ' den $160^{\circ} \mathrm{C}$ şeklinde olmuştur.

Şekil 6'de saf ve 2500 ppm glutamik asit varlığında üretilen kalsiyum sülfat dihidratın $X \quad$ 1şını kırınım profilleri verilmiştir. Saf ortamda $10^{\circ}-60^{\circ}(2 \theta)$ tarama aralığında kalsiyum sülfat dihidrat için $11,649^{\circ}, 20,731^{\circ}, 23,452^{\circ}$, $29,143^{\circ}, 31,142^{\circ}, 33,344^{\circ}, 40,629^{\circ}, 43,338^{\circ}, 47,820^{\circ}$, $48,404^{\circ}, 55,182^{\circ}$ karakteristik pikleri belirlenmiştir. Elde edilen bu pikler Uluslararası X-Işını Kırınım Veri Merkezi (ICDD) tarafindan verilen kalsiyum sülfat dihidrat pikleriyle uyumlu olup, ikinci bir faz ve amorf yapı oluşumuna rastlanmamıştır. 2500 ppm glutamik asit varlığında üretilen kalsiyum sülfat dihidratın XRD pikleri incelendiğinde glutamik asit varlığında ölçülen pik şiddeti değerlerinde bir artış olduğu belirlenmiştir. Literatürde katkılar varlığında üretilen kristallerin pik şiddetinde görülen değişim kristal yapısına söz konusu katkıların bağlanması ile açıklanmaktadır [9]. Nitekim glutamik asidin karakteristik piklerinin saf kalsiyum sülfat dihidratın pikleriyle örtüşmesi buna karşın pik şiddetinde görülen değişim benzer şekilde kalsiyum sülfat dihidrat yapısına glutamik asidin bağlandığını işaret etmektedir [10]. Şekil 7'da saf ortamda üretilen kalsiyum sülfat dihidratın ATR-FTIR spektrumu verilmiştir. Spektrumda görülen 3600-3400 $\mathrm{cm}^{-1}$ absorpsiyon bant aralığ $\mathrm{O}-\mathrm{H}$ gerilmesini, $1680 \mathrm{~cm}^{-1}$ ve 1620 $\mathrm{cm}^{-1}$ de görülen bantlar ise H-O-H eğilmesini göstermekte olup, O-H bandı ile birlikte bulunması durumunda yapıda kristalize suyun varlığını belirtmektedir. 1270 ve $1100 \mathrm{~cm}^{-1}$ de görülen bantlar $\mathrm{O}-\mathrm{H}$ grubuna karşılık gelen eğilme titreşimine aittir. $663 \mathrm{~cm}^{-1}$ ve $594 \mathrm{~cm}^{-1}$ ' de görülen bantlar ise kalsiyum sülfat dihidratın yapısında bulunan $\mathrm{SO}_{4}$ 'ın eğilme titreşimlerinden kaynaklanmaktadır [11]. 


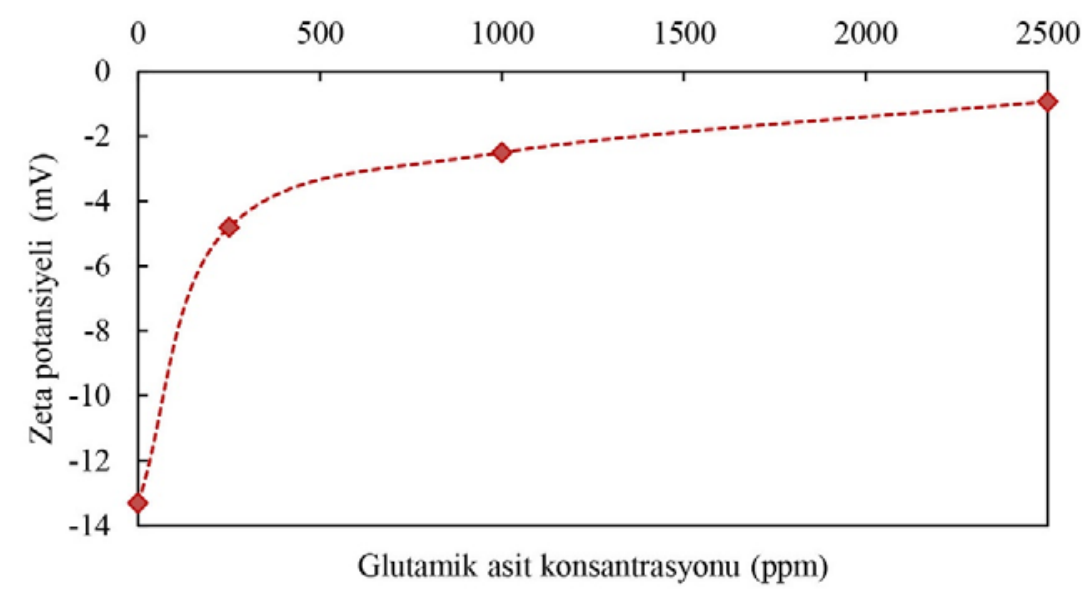

Şekil 4. Kalsiyum sülfat dihidratın glutamik asit konsantrasyonuna bağlı zeta potansiyeli değişimi (The change of zeta potential of the calcium sulfate dihydrate crystals according to glutamic acid concentration)

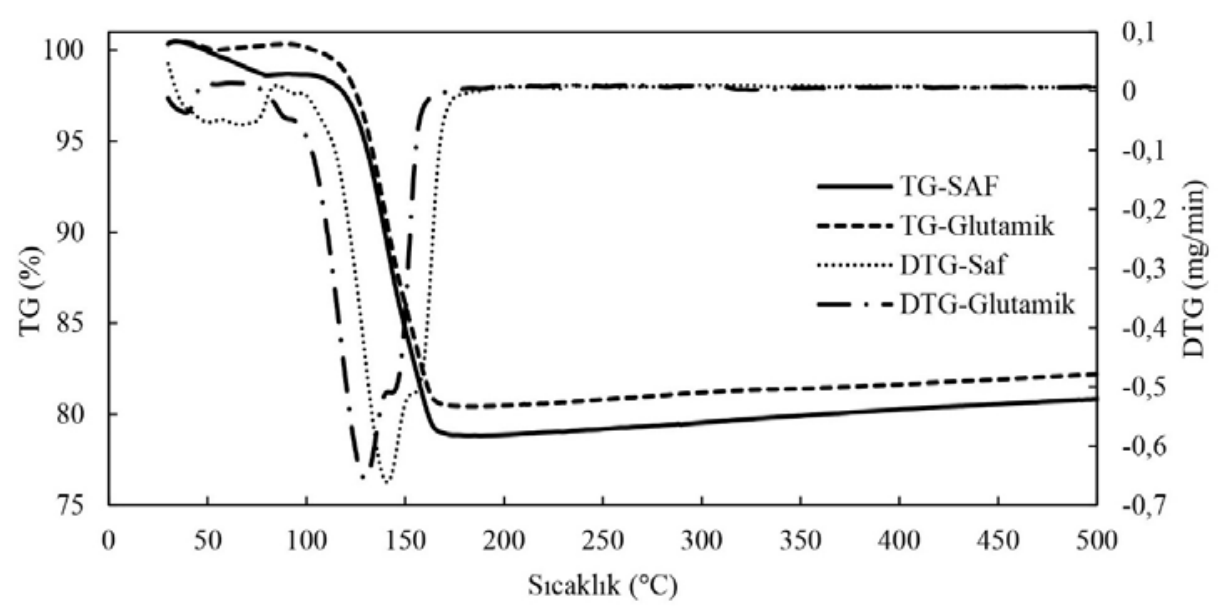

Şekil 5. Saf kalsiyum sülfat dihidrat ve 2500 ppm glutamik asit varlığında elde edilen kristallerin TGA ve DTG eğrileri (TGA and DTG curves of the calcium sulfate dihydrate crystals obtained in pure media and in the presence of $2500 \mathrm{ppm}$ glutamic acid)

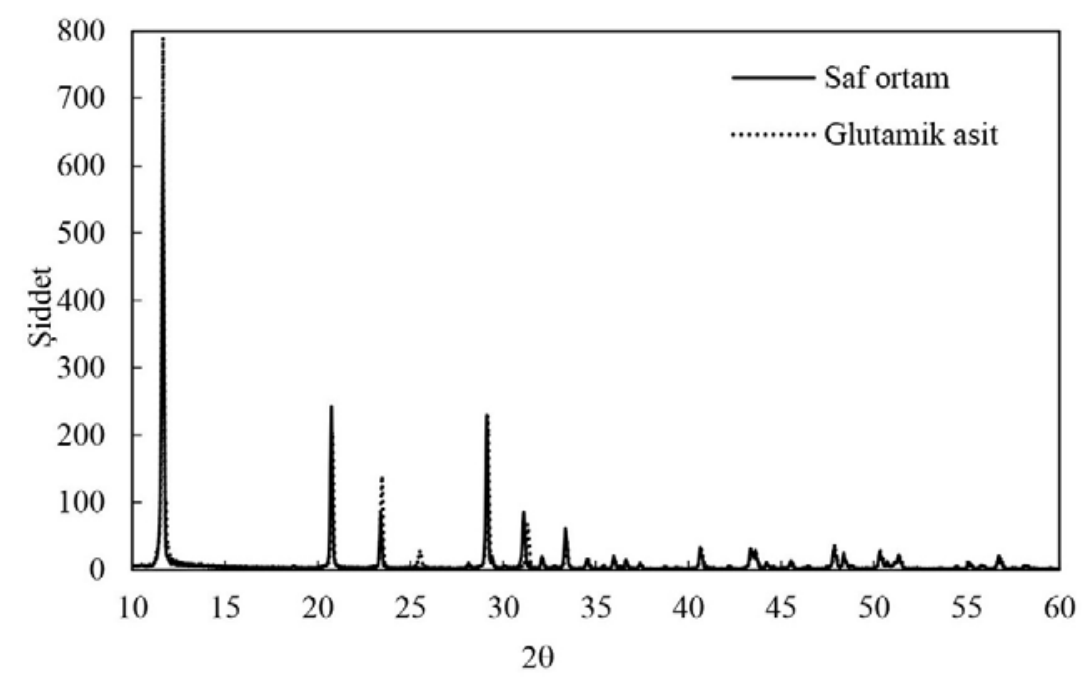

Şekil 6. Saf ve 2500 ppm glutamik asit varlığında elde edilen kalsiyum sülfat dihidrat kristallerin X 1şını kırınım profilleri (X-Ray Diffraction patterns of the calcium sulfate dihydrate crystals obtained in pure media and in the presence of $2500 \mathrm{ppm}$ glutamic acid) 
Standart referans glutamik asidin FTIR spektrumu 3400$2400 \mathrm{~cm}^{-1}$ aralığ $1 \mathrm{O}-\mathrm{H}$ gerilme titreşimini, $3500-3000 \mathrm{~cm}^{-1}$ aralığ $\mathrm{N}-\mathrm{H}$ gerilme titreşimini, $3000-2850 \mathrm{~cm}^{-1}$ aralığ $\mathrm{C}-\mathrm{H}$ gerilme titreşimini, $1725-1700 \mathrm{~cm}^{-1}$ aralığ $\mathrm{C}=\mathrm{O}$ gerilme titreşimini, $1640-1550 \mathrm{~cm}^{-1}$ aralığında $\mathrm{N}-\mathrm{H}$ eğilme titreşimini, $1465 \mathrm{~cm}^{-1} \mathrm{C}-\mathrm{H}$ eğilme titreşimini, $1300-1000 \mathrm{~cm}^{-}$ 1 aralığında C-O gerilme titreşimini ve $930 \mathrm{~cm}^{-1}$ eğilme titreşimini karakterize etmektedir [12]. Glutamik asidin kalsiyum sülfat dihidratın kristal yüzeyine tutunma şeklini belirleyebilmek için ATR-FTIR yerine daha hassas bir ölçüm yöntemi olan TGA-FTIR-MS (Setaram Labsys EvoThermo Nicolet IZ 10-Pfeiffer Omni Star) kullanılmıştır. Bu yöntemde cihazın TGA ünitesinde kontrollü olarak 1sıtılan numuneden çıkan gaz fazın transfer hatları ile FTIR ve MS ünitelerine gönderilmesi ve eşzamanlı analizlerinin yapılması sağlanabilmektedir. Bu çalışmada FTIR transfer hattı $225^{\circ} \mathrm{C}$, MS hattı ise $190{ }^{\circ} \mathrm{C}$ 'de tutulmuştur. FTIR cihazında $4000-700 \mathrm{~cm}^{-1}$ spektral aralığında fonksiyonel gruplar ve MS cihazında $\mathrm{m} / \mathrm{z}=1-300$ aralığında ise kütle/yük oranları taranmıştır. Şekil 8'de 2500 ppm glutamik asit varlığında üretilen kalsiyum sülfat dihidratın 3 boyutlu FTIR spektrumu verilmiştir. Spektrum incelendiğinde 3800-3400 $\mathrm{cm}^{-1}$ aralığında görülen $\mathrm{O}-\mathrm{H}$ gerilme titreşim bantları kalsiyum sülfatın yapısında yer alan suyu göstermektedir. $3100 \mathrm{~cm}^{-1}$ piki glutamik asidin yapısında bulunan amin ($\mathrm{NH}_{2}$ ) grubundan kaynaklanan zayıf N-H gerilimini göstermektedir. $1680-1590 \mathrm{~cm}^{-1}$ bant aralığında görülen bantlar ise N-H eğilme bandını ve $1760-1690 \mathrm{~cm}^{-1}$ aralığında görülen şiddetli $\mathrm{C}=\mathrm{O}$ titreşim bantları ise karboksilik asitlerin varlığını işaret etmektedir. Aynı zamanda, 1440$1395 \mathrm{~cm}^{-1}$ aralığında görülen bant karboksilik asitten kaynaklı O-H grubuna karşılık gelen eğilme titreşimini; $1320-1315 \mathrm{~cm}^{-1}$ aralığında görülen bant ise C-O gerilme titreşimini karakterize etmektedir. Şekil 9'da glutamik asit varlığında üretilen kalsiyum sülfat dihidrat kristallerinin FTIR ile belirlenen ve glutamik aside ait olan karakteristik pikleri sıcaklığın fonksiyonu olarak verilmiştir. Şekil 9 incelendiğinde glutamik asidin kalsiyum sülfat dihidratın yapısına bağlandığı ve $160-165^{\circ} \mathrm{C}$ sicaklık aralığında maksimum tutunmanın gerçekleştiği açıkça görülmektedir.

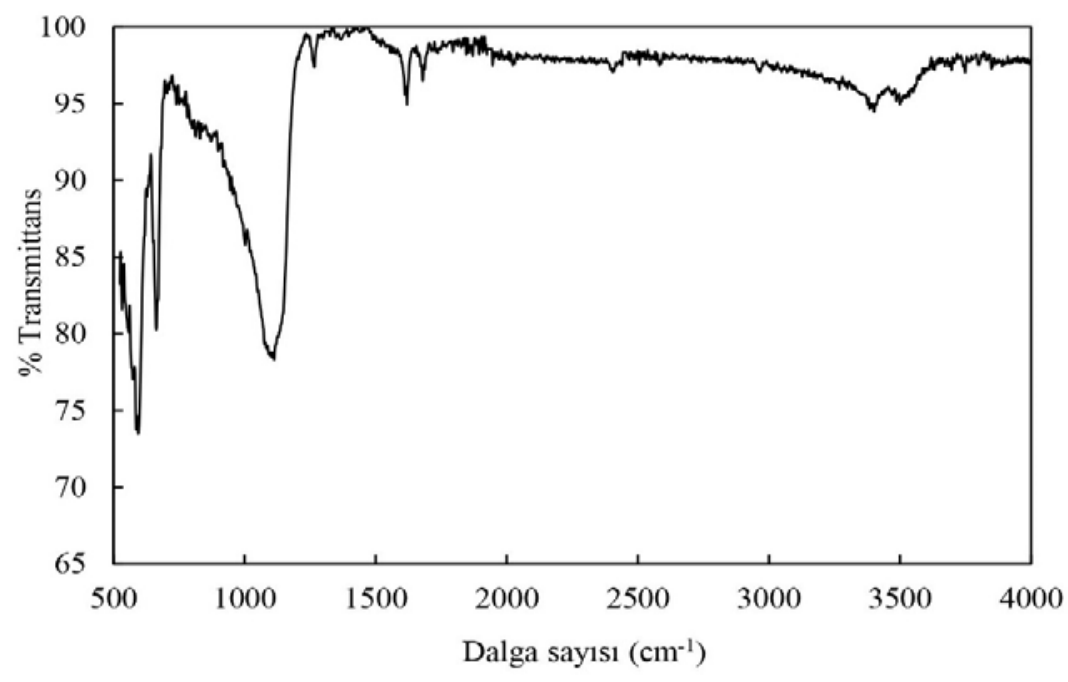

Şekil 7. Saf kalsiyum sülfat dihidrat kristallerinin FTIR spektrumu (FTIR spectrum of the calcium sulfate dihydrate crystals obtained in pure media)

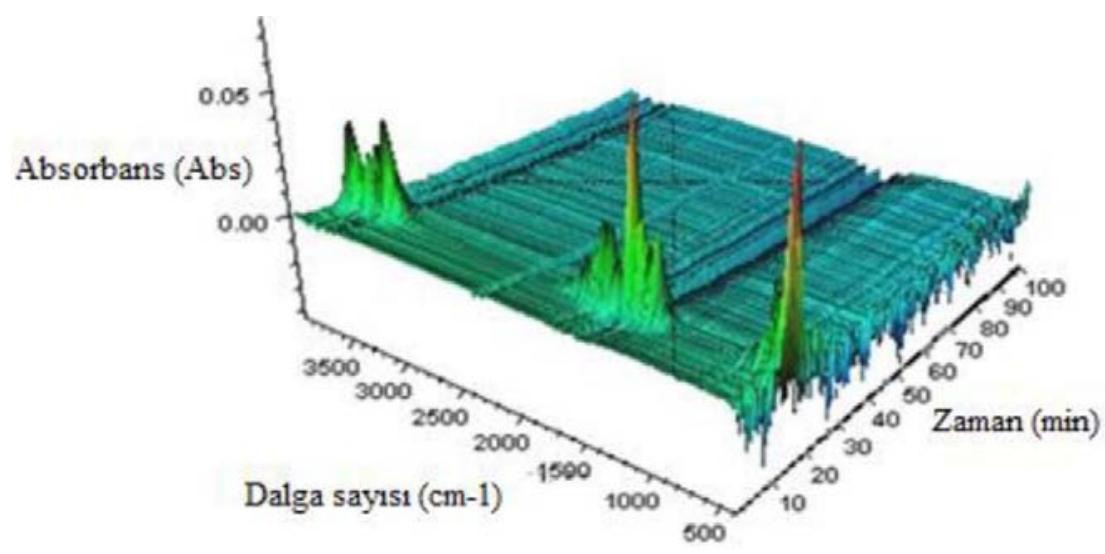

Şekil 8. 2500 ppm glutamik asit varlığında elde edilen kalsiyum sülfat dihidrat kristallerinin 3 boyutlu FTIR spektrumu (3D FTIR spectrum of the calcium sulfate dihydrate crystals obtained in the presence of $2500 \mathrm{ppm}$ glutamic acid) 
TG-MS cihazı kullanılarak $25-1000^{\circ} \mathrm{C}^{\prime} \mathrm{de}$ ve $1-300$ kütle/yük oranlarını kapsayacak şekilde yapılan ölçümlerde elde edilen sonuçlar da Şekil 10'da verilmiştir. Şekil 10'da görülen ve maksimum iyon şiddetinin ölçüldüğü $125-190^{\circ} \mathrm{C}$ sicaklık aralığında $\mathrm{m} / \mathrm{z}$ oranları $41,45,56,73,75$ ve 84 olan pikler belirlenmiştir. Bu kütle/yük oranları literatürde de belirtildiği üzere glutamik asidi karakterize etmektedir [13]. TGA-FTIR ve TGA-MS eş zamanlı analizleri glutamik asitin kalsiyum sülfat dihidrat kristallerinin yapısına bağlandığını açıkça göstermiştir. Kristal tane dağılımının belirlenmesi kristalizörlerin tasarımı ve kontrolü açısından önemli bir parametredir [13, 14].

Kristal tane dağılımı temel olarak, kristalizörde kalma süresine, nükleasyon ve büyüme kinetiğine bağlı olup say1 yoğunluğu teorisi kullanılarak belirlenebilir. Sürekli beslemeli ve sürekli ürün çekişli (MSMPR) kristalizör sayı yoğunluğu teorisinin incelenmesi açısından ideal bir kristalizör tipi olup say1 yoğunluğu denklemi Eş. 1'de gösterildiği gibi yazılabilir.

$$
\frac{\mathrm{d}[\mathrm{G}(\mathrm{L}) \mathrm{n}(\mathrm{L})}{\mathrm{dL}}+\frac{\mathrm{n}(\mathrm{L})}{\tau}=0
$$

Bu eşitlikte $G(L)$ boyuta bağlı kristal büyüme hızını, $n(L) L$ kristal boyutundaki sayı yoğunluğunu, $\tau$ ise kristalizörde kalma süresini göstermektedir [14]. Kristallerin büyüme hızının tane boyutundan bağımsız olduğu $(\mathrm{dG}(\mathrm{L}) / \mathrm{dL}=0$ ve $\mathrm{G}(\mathrm{L})=\mathrm{G}=$ sabit) ve McCabe'in $\Delta \mathrm{L}$ yasasının geçerli olduğu durumda sayı yoğunluğu denklemi Eş. 2'de gösterildiği gibi yazılabilir.

$$
\mathrm{n}(\mathrm{L})=\mathrm{n}_{0} \exp \left(-\frac{\mathrm{L}}{\mathrm{G} \tau}\right)
$$

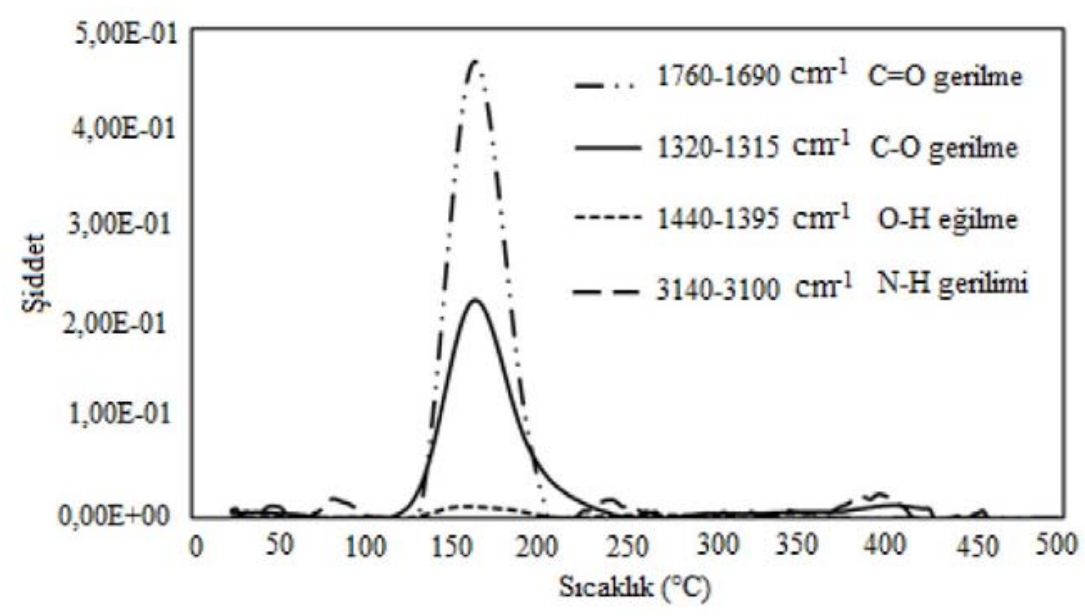

Şekil 9. 2500 ppm glutamik asit varlığında elde edilen kalsiyum sülfat dihidrat kristallerinin sıcaklığa bağlı olarak fonksiyonel gruplarının değerlendirilmesi

(Evaluation of the functional groups with respect to temperature for the crystals obtained in the presence of $2500 \mathrm{ppm}$ glutamic acid)

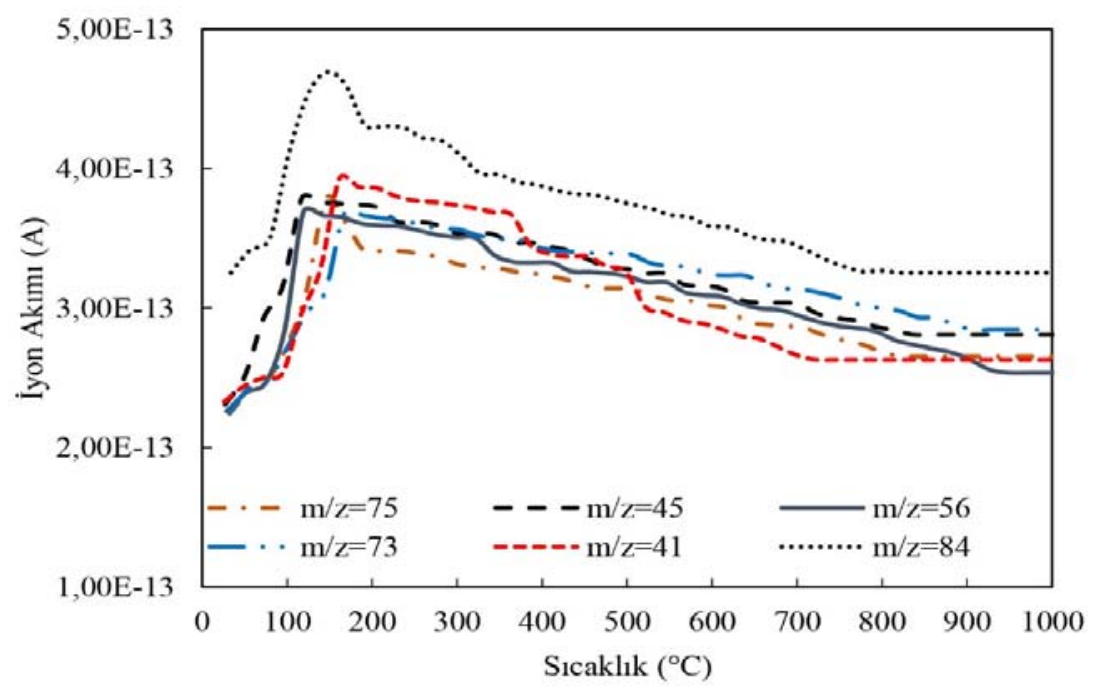

Şekil 10. 2500 ppm glutamik asit varlığında elde edilen kristallerin $\mathrm{m} / \mathrm{z}$ değerleri (The values of $\mathrm{m} / \mathrm{z}$ of the crystals obtained in the presence of $2500 \mathrm{ppm}$ glutamic acid) 
$\mathrm{Bu}$ eşitlikte $\mathrm{n}_{0}, \lim _{L \rightarrow 0} n(L)$ sıfır tane boyutundaki sayı yoğunluğunu göstermektedir. Bu durumda, $\ln (\mathrm{n})-\mathrm{L}$ değerleri grafiğe geçirildiğinde grafiğin eğimi $-1 /(\mathrm{G} \tau)$, kesim noktası ise $\mathrm{n}_{0}$ değerini veren bir doğruyu verir. Eğim ve kesim noktası değerleri kullanılarak kristal büyüme hızı ve Eş. 3 kullanarak da nükleasyon hızı hesaplanabilir [15].

$$
\mathrm{B}_{0}=\mathrm{n}_{0} \mathrm{G}
$$

Birçok kristalizasyon prosesinde sayı yoğunluğu ideal sayı yoğunluğu teorisinden sapma gösterebilmektedir. Bu sapma, boyuta bağlı büyüme, mekanik etki sonucu kristallerde kırılma veya aşınma, aglomerasyon, sınıflanma etkisi, yatışkın olmayan koşullar ve yetersiz karışma gibi nedenlere bağlı olarak ortaya çıkabilmektedir. Boyuta bağlı büyümenin olduğu ve McCabe'in $\Delta \mathrm{L}$ yasasının geçerli olmadığı durumda kullanılmak üzere büyüme hızını belirlemek için literatürde önerilmiş çeşitli ampirik eşitlikler mevcuttur [16]. Bu çalışmada, Tablo 1'de verilen kinetik modeller saf ve farklı glutamik asit varlığında üretilen kalsiyum sülfat dihidratın büyüme hılarının hesaplanmasında kullanılmıştır. Tablo 1'de verilen eşitliklerde a, b ve c katsayıları büyüme model parametrelerini, $\mathrm{G}_{0}$ nüklei büyüme hızını, Gm büyük kristallerin sınırlayıcı büyüme hızını, L* seçilen bir kristal için tane boyutunu, $n *$ ise seçilen $L^{*}$ tane boyutundaki kristalin say1 yoğunluğunu göstermektedir [17]. İntegral sınır koşulları en küçük tane boyutundaki kristal ile kristalizördeki en büyük kristalin tane boyutu olarak belirlenmiştir. $\mathrm{Bu}$ çalışmada, saf ortamda üretilen kalsiyum sülfat dihidrat kristallerinin say1 yoğunluğu değerlendirmesi boyuttan bağımsız ve boyuta bağlı büyümenin olduğu durum için yapılmış ve her bir modele ait korelasyon katsay1s1, ortalama hata kareleri (MSE) ve varyans ((RMSD) $)^{2}$ ) değerleri hesaplanmıştır. Elde edilen sonuçlar Şekil 11 ve Tablo 2'de verilmiştir. Şekil 11 'den görüldüğü üzere, kalsiyum sülfat dihidrat kristallerinin büyüme hızı boyuta bağlı davranış göstermektedir. Ayrıca, ASL, C-R, MJ2 ve MJ3 modelleri için korelasyon katsayısının 1'e yakın çıkması deneysel

Tablo 1. Kinetik model eşitlikler (The kinetic model equations)

\begin{tabular}{lll}
\hline Model & Büyüme Hız1 Denklemi & Say1 yoğunluğu denklemi \\
ASL & $\mathrm{G}(\mathrm{L})=\mathrm{G}_{0}(1+\mathrm{aL})^{\mathrm{b}}$ & $\mathrm{n}(\mathrm{L})=\mathrm{n}_{0}(1+\mathrm{aL})^{-\mathrm{b}} \exp \left(\frac{1-(1+\mathrm{aL})^{1-\mathrm{b}}}{1-\mathrm{b}}\right)$ \\
C-R & $\mathrm{G}(\mathrm{L})=\mathrm{G}_{0}(1+\mathrm{aL})$ & $\mathrm{n}(\mathrm{L})=\mathrm{n}_{0}(1+\mathrm{aL})^{\left(\frac{-1-\mathrm{b}}{\mathrm{b}}\right)}$ \\
MJ2 & $\mathrm{G}(\mathrm{L})=\mathrm{G}_{\mathrm{m}}[1-\exp (-\mathrm{aL})]$ & $\mathrm{n}(\mathrm{L})=\mathrm{n} * \exp \left[\mathrm{a}\left(\mathrm{L}-\mathrm{L}^{*}\right)\right]\left(\frac{\exp (\mathrm{aL})-1}{\exp (\mathrm{aL})-1}\right)^{\frac{(-1-\mathrm{b})}{\mathrm{b}}}$ \\
MJ3 & $\mathrm{G}(\mathrm{L})=\mathrm{G}_{\mathrm{m}}[1-\exp [-\mathrm{a}(\mathrm{L}+\mathrm{c})]]$ & $\mathrm{n}(\mathrm{L})=\mathrm{n}_{0} \exp (\mathrm{aL})\left(\frac{\exp [\mathrm{a}(\mathrm{L}+\mathrm{c})]-1}{\exp (\mathrm{ac})-1}\right)^{\frac{(-1-\mathrm{b})}{\mathrm{b}}}$ \\
\hline
\end{tabular}

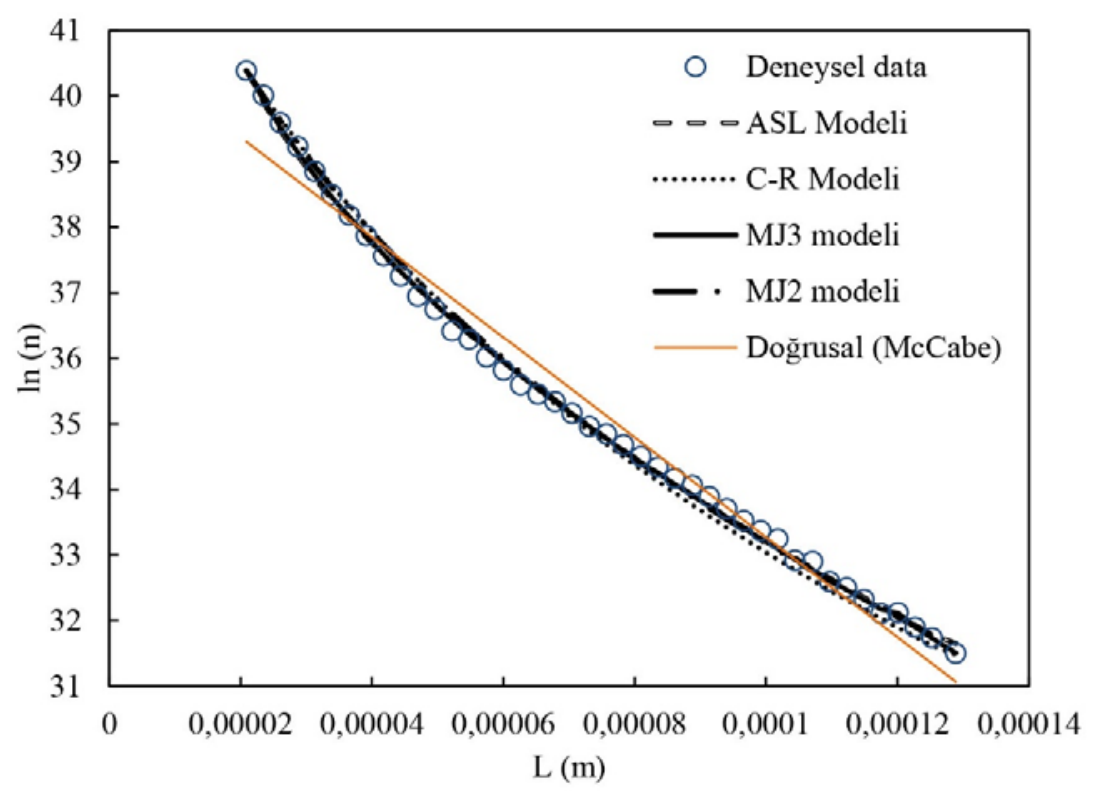

Şekil 11. Saf ortamda üretilen kalsiyum sülfat dihidratın boyuttan bağımsız ve boyuta bağlı modellere göre sayı yoğunluğu değerlendirmesi

(Population density evaluation of pure calcium sulfate dihydrate crystals according to size-independent and size dependent models) 
olarak elde edilen ve boyuta bağlı büyüme modelleri ile edilen değerler bu sonucu desteklemektedir. Tablo 2'deki sonuçlar göz önüne alındığında, saf ve incelenen tüm glutamik asit konsantrasyonları kalsiyum sülfat dihidrat kristalizasyonunun büyüme kinetiğinin MJ3 modeliyle daha iyi karakterize edilebileceği belirlenmiştir.

Saf ve üç farklı glutamik asit konsantrasyonu için hesaplanan ASL, C-R, MJ2 ve MJ3 modellerine ait kinetik parametreler Tablo 3'de verilmiştir. MJ3 kinetik modeli MJ2 modelinin geliştirilmesi ile elde edilen 3 parametreli büyüme hızı modeli olup a katsayısı boyuta bağlı büyüme şiddetini, c katsayısı da sıfira yakın tane boyutundaki kristallerin büyüme hızını etkileyen bir parametreyi göstermektedir. b parametresi ise sabit bir katsayı olup $0<\mathrm{b}<1$ aralı̆ıında değişmektedir. Glutamik asit varlığında hesaplanan a katsayısının konsantrasyon artışına bağlı olarak azalma göstermesi boyuta bağlı büyüme hızının şiddetini artığını işaret etmektedir. Ayrıca, Tablo 3'ün incelenmesinden de açıça görüleceği üzere, kalsiyum sülfat dihidratın kristal büyüme hızı glutamik asit konsantrasyonun artş̧ıla azalmaktadır.

Tablo 2. ASL, C-R, MJ2 ve MJ3 modellerine ait korelasyon katsayısı, hata (\%) ve varyans değerleri (The calculated values of the relative coefficient, mean square error and variance of ASL, C-R, MJ2 and MJ3 models)

\begin{tabular}{lllll}
\hline $\begin{array}{l}\text { Katk1 miktar1 } \\
(\mathrm{ppm})\end{array}$ & Model & Korelasyon Katsay1s1 & MSE & Varyans \\
\hline \multirow{4}{*}{0} & McCabe & 0,9758 & - & - \\
& ASL & 0,9989 & 0,4072 & 0,0171 \\
& C-R & 0,9982 & 0,5535 & 0,0339 \\
MJ2 & 0,9984 & 0,4744 & 0,0242 \\
\hline \multirow{3}{*}{50} & MJ3 & 0,9991 & 0,3496 & 0,0128 \\
\hline & McCabe & 0,9540 & - & - \\
& ASL & 0,9987 & 0,3884 & 0,0185 \\
& C-R & 0,9982 & 0,4626 & 0,0268 \\
MJ2 & 0,9989 & 0,6246 & 0,0476 \\
& MJ3 & 0,9992 & 0,2698 & 0,0091 \\
\hline \multirow{4}{*}{25000} & McCabe & 0,9802 & - & - \\
& ASL & 0,9963 & 0,7357 & 0,0559 \\
& C-R & 0,9976 & 1,0580 & 0,0311 \\
& MJ2 & 0,9990 & 0,9190 & 0,0889 \\
& MJ3 & 0,9995 & 0,3809 & 0,0180 \\
\hline & McCabe & 0,9806 & - & - \\
& ASL & 0,9981 & 0,6502 & 0,0497 \\
& C-R & 0,9972 & 0,7859 & 0,0703 \\
& MJ2 & 0,9994 & 0,7580 & 0,0733 \\
& MJ3 & 0,9997 & 0,6206 & 0,0454 \\
\hline
\end{tabular}

Tablo 3 . ASL, C-R, MJ2 ve MJ3 modellerine ait kinetik parametreler (Kinetic parameters of ASL, C-R, MJ2 and MJ3 models)

\begin{tabular}{lllllll}
\hline \multirow{2}{*}{$\begin{array}{l}\text { Katk1 miktar1 } \\
(\mathrm{ppm})\end{array}$} & Model & \multicolumn{6}{l}{$\begin{array}{l}\mathrm{a} \times 10^{6} \\
\left(\mathrm{~m}^{-1}\right)\end{array}$} & $\mathrm{b}$ & $\begin{array}{l}\mathrm{c} \times 10^{6} \\
(\mathrm{~m})\end{array}$ & $\mathrm{G}^{*} \times 10^{-9}\left(\mathrm{~m}_{\mathrm{n}} \mathrm{s}^{-1}\right)$ & $\begin{array}{l}\mathrm{G}_{\mathrm{m}} \times 10^{-8} \\
\left(\mathrm{~m}^{-1} \mathrm{~s}^{-1}\right)\end{array}$ \\
\hline \multirow{3}{*}{0} & ASL & 2,100 & 0,391 & - & 0,27 & - \\
& C-R & 0,018 & 0,137 & - & 4,23 & - \\
& MJ2 & 0,020 & 0,402 & - & - & 2,764 \\
& MJ3 & 0,005 & 0,201 & 40,8 & - & 2,233 \\
\hline \multirow{3}{*}{250} & ASL & 0,274 & 0,451 & - & 2,03 & - \\
& C-R & 0,027 & 0,189 & - & 3,89 & - \\
& MJ2 & 0,017 & 0,349 & - & - & 1,14 \\
& MJ3 & 0,032 & 0,580 & 9,8 & - & - \\
1000 & ASL & 0,230 & 0,410 & - & 2,42 & - \\
& C-R & 0,013 & 0,080 & - & 3,42 & 0,95 \\
& MJ2 & 0,019 & 0,325 & - & - & 0,96 \\
\hline \multirow{3}{*}{2500} & MJ3 & 0,030 & 0,520 & 14,29 & - & - \\
& ASL & 0,195 & 0,205 & - & 2,85 & - \\
& C-R & 0,033 & 0,195 & - & 3,28 & 0,67 \\
& MJ2 & 0,030 & 0,360 & - & - & 0,27 \\
\hline
\end{tabular}




\section{SONUÇLAR (CONCLUSIONS)}

Kalsiyum sülfat dihidat kristalizasyonunun glutamik asit varlığında incelendiği bu çalışmada ürün kristallerinin ortalama tane boyutunun ve filtrasyon karakteristiğinin glutamik asit konsantrasyonuna bağlı olarak değiştiği belirlenmiştir. Zeta potansiyel ölçümleri, XRD, TGA-FTIRMS ve SEM analizleri ile glutamik asidin kalsiyum sülfat dihidratın büyüyen kristal yüzeylerine elektrostatik etkileşim ve seçimli yüzey adsorbsiyon mekanizması ile bağlanarak kristal morfolojisinde değişime neden olduğu gösterilmiştir. Aynı zamanda glutamik asidin kristalizasyon ortamında yer alması durumunda kristal büyüme hızının ve nükleasyon hızının, bir başka deyişle kristalizasyon kinetiğinin değiştiği belirlenmiştir. Kinetik hesaplamalar ile de kalsiyum sülfat dihidrat kristallerinin büyüme hızının boyuta bağlı davranış gösterdiği ve büyüme kinetiğinin incelenen modeller içerisinde MJ3 modeliyle daha iyi karakterize edilebileceği gösterilmiştir. Elde edilen bu sonuçlar endüstriyel açıdan irdelendiğinde, glutamik asidin katk1 maddesi olarak kullanılması durumunda 1sı değiştiricilerde, borularda ve tanklarda oluşan kabuğun daha zayıf karakterli oluşumuna neden olacağı ve kolaylıkla temizlenebilmesine imkan sağlayacağı belirlenmiştir.

\section{TEŞEKKÜR (ACKNOWLEDGEMENT)}

$\mathrm{Bu}$ çalı̧̧ma, Marmara Üniversitesi Bilimsel Araştırma Projeleri Birimi tarafindan FEN-A-080715-0340 nolu proje kapsamında desteklenmiştir.

\section{KAYNAKLAR (REFERENCES)}

1. Titiz-Sargut S., Sayan P., Avc1 B., Influence of citric acid on calcium sulfate dihydrate crystallization in aqueous media, Cryst. Res. Technol., 42 (2), 119-126, 2007.

2. Rabizadeh T., Stawski T.M., Morgan D.J., Peacock C.L., Benning L.G., The effects of inorganic additives on the nucleation and growth kinetics of calcium sulfate dihydrate crystals, Cryst. Growth Des., 17 (2), 582-589, 2017.

3. Rabizadeh T., Peacock C.L., Benning L.G., Carboxylic acids: effective inhibitors for calcium sulfate precipitation? Miner. Mag., 78 (6), 1465-1472, 2014.

4. Amjad Z., Gypsum scale formation on heat exchanger surfaces: The influence of natural and synthetic polyelectrolytes, Tenside Surf., 41, 214-219, 2004.

5. Feldmann T., Demopoulos G.P., Influence of impurities on crystallization kinetics of calcium sulfate dihydrate and hemihydrate in strong $\mathrm{HCl}-\mathrm{CaCl}_{2}$ solutions, Ind. Eng. Chem. Res., 52 (19), 6540-6549, 2013.

6. Ben Ahmed S., Tlili M.M., Ben Amor M., Influence of a polyacrylate antiscalant on gypsum nucleation and growth, Cryst. Res. Technol., 43 (9), 935-942, 2008.

7. Beckmann W., Crystallization basic concepts and industrial applications, Wiley-VCH Verlag $\mathrm{GmbH}$ \& Co. KGaA, Almanya, 2013.

8. Fukami T., Tahara S., Nakasone K., Yasuda C., Synthesis, crystal structure, and thermal properties of $\mathrm{CaSO}_{4} \cdot 2 \mathrm{H}_{2} \mathrm{O}$ single crystals, Int. J. Chem., 7 (2), 12-20, 2015.

9. Ceyhan A.A., Baytar O., Gülce A., Effect of heavy metals impurities upon nucleation kinetics of $\mathrm{NaCl}$, Journal of the Faculty of Engineering and Architecture of Gazi University, 29 (1), 95-103, 2014.

10. Vani R., Girija E.K., Palanichamy M., Narayana Kalkura S., Simultaneous crystallization of calcium phosphate and calcium oxalate in the presence of ascorbic acid under physiological conditions, Mater. Eng. Sci. C, 29 (4), 1227-1232, 2009.

11. Al Dabbas M., Eisa M.Y., Kadhim W.H., Estimation of gypsum- calcite percentages using a fourier transform infrared spectrophotometer (FTIR), in Alexandria Gypsiferous Soil -Iraq, Iraqi J. Sci, 55 (4B), 1916-1926, 2014.

12. Pavia D.L., Lampman G.S., Kriz G.S., Vyvyan J.R., Introduction to Spectroscopy, 4th Edition, Brooks-Cole, Cengage Learning, Belmont, 2009.

13. National Institute of Standards and Technology (NIST) Mass Spectrometry Data Center Collection. L-Glutamic Acid. http://webbook.nist.gov/cgi/cbook.cgi?ID=C56860\&M ask $=200.2014$.

14. Mydlarz J., Jones A.G., On numerical computation of size-dependent crystal growth rates, Comput. Chem. Eng., 13 (8), 959-965, 1989.

15. Matyania A., Koralewska J., Wierzbowska B., Piotrowski K., The influence of process parameters on struvite continuous crystallization kinetics, Chem. Eng. Commun., 193 (2), 60-176, 2006.

16. Mydlarz J., Jones A.G., An assessment of MSMPR crystallization kinetics data for systems modelled by size-dependent crystal growth rate functions, Chem. Eng. J., 55 (1-2), 69-80, 1994.

17. Li X., Song X., Liu G., Yu J., Size-dependent nucleation and growth kinetics model for potassium chlorideApplication in Qarhan Salt Lake, J. Cryst. Growth., 311 (11), 3167-3173, 2009. 